\title{
PINTURAS, ORNAMENTOS Y OTROS RECAUDOS. LA CIRCULACIÓN DE "TRASTOS" ENTRE LAS CAPILLAS ESPAÑOLAS DE LONDRES Y LA HAYA, 1662-1665*
}

\author{
Cristina Bravo Lozano ${ }^{1}$ \\ Universidad Autónoma de Madrid
}

\begin{abstract}
La capilla de la embajada española en Londres representó un eje referencial en la política confesional de la monarquía de España en la segunda mitad del siglo XVII. Como espacio público de culto y ámbito de sociabilidad política se dotó de elementos artísticos y ornamentales proporcionados a la dignidad del monarca patrocinador. El estudio de la naturaleza de estos objetos, su uso y funcionalidad dentro de la cultura material permite conocer cómo en la década de 1660 circularon entre ambas orillas del mar del Norte y constituyeron una parte esencial del patrimonio artístico y litúrgico del oratorio diplomático.
\end{abstract}

Palabras clave: Capilla; diplomacia; cultura material; catolicismo; Londres; La Haya; monarquía de España, siglo XVII.

\section{PICTURES, ORNAMENTS AND OTHER OBJECTS. THE MOVEMENT OF RELIGIOUS ARTEFACTS BETWEEN THE SPANISH CHAPELS OF LONDON AND THE HAGUE, 1662-1665}

The chapel of the Spanish embassy in London had an important role to play in the confessional politics of the Spanish monarchy in the second half of the $17^{\text {th }}$ century. As a public space of worship and political social exchange, it was well equipped with artistic and ornamental elements. The study of these objects, their nature, uses and functionality within the material culture of the period shows how they circulated back and forth across the North Sea during the 1660 's and how they constituted an essential part of the artistic and liturgical patrimony of this diplomatic chapel.

Key words: Chapel; diplomacy; material culture; Catholicism; London; The Hague; Spanish Monarchy; $17^{\text {th }}$ century.

Como citar este artículo / Citation: Bravo Lozano, Cristina (2018): "Pinturas, ornamentos y otros recaudos. La circulación de 'trastos' entre las capillas españolas de Londres y La Haya, 1662-1665”. En: Archivo Español de Arte, vol. 91, núm. 361, Madrid, pp. 17-28. https://doi.org/10.3989/aearte.2018.02

\footnotetext{
* Este trabajo se ha realizado al amparo del programa Juan de la Cierva-Incorporación (IJCI-2016-30430) y se incluye en el marco de los proyectos de la Dirección General de Investigación del MINECO El modelo policéntrico de soberanía compartida (siglos XVI-XVIII). Una vía alternativa a la construcción del Estado moderno (HAR201345357-P) y Sociedad cortesana y redes diplomáticas: la proyección europea de la monarquía de España (1659-1725) (HAR2015-67069-P MINECO/FEDER).

1 cristina.bravo@uam.es / ORCID iD: http://orcid.org/0000-0001-9919-1270.
} 
A finales de 1670, poco después de su llegada a la corte de Londres como enviado ordinario del Rey Católico, Marcos Alberto de Oñate calificó la capilla de su embajada como "la mayor

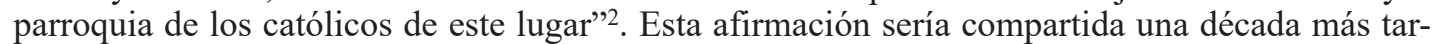
de por el protestante lombardo Gregorio Leti, quien distinguió el oratorio del entonces legado español, Pedro Ronquillo, como "se cathedrale fosse in paesi di cattolici"'. Sendas consideraciones evocan la dignidad adquirida por este espacio de culto en el entorno diplomático. Trascendiendo sus proporciones físicas o su posición estratégica en el entramado urbano, la idiosincrasia de este altar radicó en su evolución institucional hacia centro de poder católico, de atracción popular y de negociación política. El carácter proselitista determinó su fábrica y se materializó en aquellos objetos que lo definían como ámbito sacro.

Desde la perspectiva de la cultura material, este estudio indagará en el proceso de configuración de un oratorio diplomático, atendiendo a las intervenciones estructurales para su acomodo y su decoración con pinturas y ornamentos de diversa naturaleza ${ }^{4}$. Las cuentas de los embajadores y los inventarios de bienes conservados aportan datos de interés para reconstruir la distribución y adorno de un lugar para la praxis devocional que, de origen particular, se abrió a la comunidad católica local y se situó a la altura de las capillas reales. Asimismo, la conexión con otros altares de embajadas españolas en urbes protestantes, caso de La Haya, se evidenció en la circulación de muchos de aquellos objetos que constituían parte de su patrimonio artístico y funcional $1^{5}$. El análisis de este traslado y posterior devolución permite conocer determinados usos acostumbrados en los negociados y las redes mercantiles por las que se canalizaron a ambos lados del mar del Norte.

\section{Un altar católico entre negociados diplomáticos}

La designación de un representante ante una corte extranjera se acompañaba de las pertinentes instrucciones. Entendidas como una relación pautada de preceptos se destinaron a reglamentar el proceder y estilo negociador del ministro español. Tales disposiciones sobre el ordenamiento de la embajada y su actividad no fueron meras orientaciones, determinaban formalmente su praxis gubernativa como delegados de la autoridad regia ${ }^{6}$. Junto a las diligencias en materia política para salvaguardar los intereses de la monarquía y hacer valer su posición en el escenario europeo y su proyección atlántica, los asuntos religiosos también se advirtieron como una de sus primeras obligaciones ${ }^{7}$. Con particular énfasis a los embajadores señalados para Londres y La Haya, destinos protestantes, se les encomendó que se condujesen con prudencia en esta materia, preservando el respeto y la tolerancia hacia las prácticas católicas ${ }^{8}$. Como garantes del Rey Católico, debían regirse por la ejemplaridad y la disimulación como métodos de adoctrinamiento, así como el proselitismo iconográfico y declamatorio. En este entramado de diplomacia confesional, los espacios sacros se articularían como baluarte misionero y lugar de socialización política.

Con el inicio de la Restauración en Inglaterra, la capilla de la embajada española en Londres retomó su camino hacia la representatividad que había tenido, circunstancialmente, desde la le-

${ }^{2}$ Carta de Marcos Alberto de Oñate a Diego de la Torre, Londres, 10 de diciembre de 1670, Archivo General de Simancas, Simancas (AGS), Estado, legajo 3972.

${ }^{3}$ Leti, 1685: 671-672.

${ }^{4}$ La significatividad material de los objetos en el siglo XVII se expone en Ago, 2006.

5 Bravo Lozano, 2015: 213-240.

${ }^{6}$ Watkins, 2008: 1-14; Storrs, 2012: 21-53; y Carrió-Invernizzi, 2013: 99-109.

7 Para la revalorización de la política confesional en el reinado de Carlos II, vid. Storrs, 2009: 25-46, en particular, 36-37.

${ }^{8}$ Instrucción para el conde de Molina, Madrid, 5 de julio de 1670, Archivo Histórico Nacional, Madrid (AHN), Estado, legajo 3456, caja 1, exp. 18. Como para las Provincias Unidas, José Pablo Alzina ofrece sintéticos datos biográficos sobra la actividad diplomática de los embajadores españoles en Londres, vid. Alzina, 2001: 120-134. Para sus instrucciones durante la primera mitad del siglo XVII, vid. Sanz Camañes, 2015: 11-31. 
gacía de Pedro de Zúñiga, marqués de Flores Dávila hasta Alonso de Cárdenas ${ }^{9}$. Por su parte, en la de La Haya sus usos ya se habían asentado y regularizado desde el establecimiento de las relaciones diplomáticas con las Provincias Unidas en $1649^{10}$. Su consideración de oratorio particular, con un altar móvil en una pequeña estancia para el servicio religioso de la familia y criados del ministro, progresivamente adquirió carácter público ${ }^{11}$. Esta apertura a la comunidad local lo convertiría, además de un ámbito de representatividad religiosa y política, en un popular polo de atracción donde hacer visible la imagen del rey de España como pater de los católicos en la corte británica y la urbe neerlandesa. Tal praxis de conservación religiosa fue posible por la permanencia estable de la embajada, de acuerdo al cargo y la condición que portaban los legados. Esto implicaba la disposición de medios para el mantenimiento de una capilla proporcionada a la dignidad del monarca patrocinador que la distinguiría de las del resto de representantes europeos. Constituía, asimismo, un espacio de rivalidad ceremonial con la otra gran potencia católica del momento, Francia, que aspiraba a entorpecer la política de acercamiento de Madrid hacia las potencias marítimas, lo que, al mismo tiempo, permitía reforzar el papel crucial de Bruselas en la política regia en el Norte.

La elección de la residencia en que establecer la embajada fue consustancial al nombramiento de ministro. A esto se sumaba la precisión de fabricar un oratorio con su valedor regio ${ }^{12}$. El edificio más a propósito había de ubicarse en un punto neurálgico de la ciudad, cerca de los centros de poder políticos y las esferas cortesanas para favorecer su actividad diplomática, así como disponer de espacio suficiente para acomodar un lugar de culto de ciertas dimensiones para un aforo elevado. La tendencia de los embajadores fue el mantenimiento del mismo inmueble concertado por sus predecesores, aunque esta estabilidad también sufrió distintas mutaciones a finales del siglo XVII. Factores externos de diversa índole forzaron la mudanza de la embajada y el inicio de nuevas pesquisas, cuya anticipación solía recaer en los cónsules y agentes españoles, o, incluso, en los ministros salientes ${ }^{13}$.

Tras cinco años de guerra con la Commonwealth, y mientras se pensionaba y apoyaba a los partidarios del bando realista en el exilio, con la restauración de Carlos II en el solio británico la monarquía de España restableció sus relaciones con Inglaterra ${ }^{14}$. A fines de 1660, el barón de Watteville, fue el primer embajador que envió Felipe IV a la corte Estuardo ${ }^{15}$. Como su antecesor en el cargo, Alonso de Cárdenas, fijó su residencia en la York House, propiedad de George Villiers, duque de Buckhingham ${ }^{16}$. La vivienda se localizaba en la ribera del Támesis, en los aledaños del palacio de Whitehall. Esta proximidad al núcleo de la administración inglesa y la élite política se vio complementada con las condiciones estructurales del inmueble. En distintas piezas podía acoger el altar del ministro y de la feligresía católica londinense ${ }^{17}$.

\footnotetext{
9 En relación con la capilla de Alonso de Cárdenas y el resto de oratorios diplomáticos en la corte londinense, vid. Trimble, 1946: 100-107, y Loomie, 1987: 402-417.

10 Sobre establecimiento diplomático entre la monarquía de España y las Provincias Unidas tras la paz de Westfalia, vid. Herrero Sánchez, 2000.

11 Kaplan, 2002: 341-361.

12 Para una visión panorámica de las composiciones y fábricas de las embajadas inglesas en cortes extranjeras, vid. Jacobsen, 2012.

13 Ochoa Brun, 2006: 274-275.

14 Alloza, 2015.

15 Charles Watteville de Joux, barón de Watteville y señor de Corbiers (1605-1670). Natural del Franco Condado, este aristócrata y militar combatió en la guerra de los Treinta Años en el frente italiano. Tras la paz de Westfalia, se hizo cargo de la capitanía general de Guipúzcoa. En 1660, Felipe IV le designó embajador en Londres hasta su salida dos años después. De vuelta a España, fue apresado y durante la regencia de Mariana de Austria, además de ser condecorado con el collar del Toisón de Oro, volvería a ejercer su actividad diplomática primero en Roma y, después, en Lisboa, donde fallecería.

16 Ibidem, 279.

${ }^{17}$ La historia de la York House, así denominada por la pretérita propiedad del arzobispo homónimo, se recoge en Cunningham, 1849: 929-931.
} 
La capilla edificada por el aristócrata borgoñón, separada de las habitaciones privadas de la embajada, debió brillar por el realce de su planta y la profusión decorativa ${ }^{18}$. Según los modelos normalizados y los gustos de la estética barroca, este eje de religiosidad española y ceremonial cortesano se ejecutó en dos fases diferenciadas. Dada la especificidad del espacio, se trataba de crear un ambiente sacro adaptado a las necesidades y exigencias materiales de la comunidad. La primera intervención siguió a la efectiva toma de posesión del edificio. En su diseño, el inglés Edward Ordof, maestro encargado de la fábrica, buscó la amplitud de la estancia, guiándose por el pragmatismo y la finalidad de la obra ${ }^{19}$. Compuesta de un solo cuerpo, para su construcción se desahogó la planta baja de la casa. Se desecharon algunas paredes y se quitaron "la tablazón y maderamen de dos salones que había sobre ella, dejándola libre hasta el tejado". Esta pieza diáfana se cubrió con bóvedas de yeso y se blanquearon las paredes laterales para intensificar la sensación de verticalidad y profundidad. El altar mayor, con sus correspondientes gradas, se dispuso bajo un dosel carmesí labrado, arrimado a la pared forrada de pino para proteger las pinturas de las humedades. La parte superior se decoró con un ciclo pictórico del apostolado. Los lienzos enmarcados se distribuyeron "en tres hileras, una sobre otra, y cuatro en cada hilera". Sobre estos, a modo de coronamento, y para que actuase como eje referencial en la colocación del conjunto, se dispusieron otros tres "del Salvador, Nuestra Señora y la Magdalena". Este programa iconográfico, tan desarrollado en la Europa postridentina por artistas como el Greco, Rubens o José de Ribera, permite distintas lecturas y lo reviste de un acusado valor simbólico. Se desconocen aspectos de interés artístico como su autoría, estilo, formato, estructura compositiva o procedencia de las piezas por su escueta enumeración en las cuentas de los embajadores y los inventarios posteriores. No obstante, la calculada ubicación en el lugar más visible de la capilla y la temática de la serie, que se exhibía completa, parecen advertir la intencionalidad adoctrinadora y proselitista de la corona con la colocación de los máximos exponentes del ejercicio misionero.

Conforme a las convenciones de la época para la distribución de los recintos religiosos católicos, a ambos lados del altar se acomodaron cuatro tribunas, superpuestas dos a dos, para acoger a "personas particulares". Esta jerarquización del espacio se rigió por la etiqueta cortesana, ubicando en una posición privilegiada a la gentry católica que eligió la capilla de España para sus devociones. En esta atmósfera de sacralidad, el oratorio también se constituyó como un lugar de reunión. Se creaba, así, otra vía de negociación informal para ganar voluntades y contribuir a los intereses regios en aquella corte.

El presbiterio se cerró con balaustradas para la comunión, situándose a sus pies el púlpito con su guardapolvo para los sermones de las festividades y días señalados. En la nave se abrieron ventanas con vidrieras para que entrase luz natural. En ambas paredes, a la altura media del cuerpo principal, se colocaron dos telas de "un Crucifijo y Nuestra Señora", una frente a otra. El resto del oratorio se cubrió con bancos de madera hasta la puerta de entrada, abierta frente al altar, debajo del coro. Al lado de la capilla también se habilitó un aposento para servir de sacristía, con tres cajones donde guardar los ornamentos; y, otro, destinado al confesionario.

El establecimiento de una embajada fuerte en Londres implicó el mantenimiento de un oratorio que se correspondiese con esta idea. Con cabida para más de mil quinientas personas, los días de fiesta el concurso de fieles desbordaba su aforo, según el testimonio del embajador. Watteville, en su manifiesta rivalidad con Francia por la exteriorización de la representación, ponderó la popularidad de su capilla, siendo "una de las de mayor capacidad que ha tenido hasta ahora ningún embajador católico en Londres" 20 .

Para dotarla de mayor espaciosidad, en la segunda intervención de mediados de 1661 se redimensionó el espacio para acoger a las personas que no entraban en el cuerpo central. Aprove-

\footnotetext{
18 La relación de la diplomacia con el arte se aborda en Colomer, 2003.

19 Cuentas de la capilla de la embajada española en Londres, Madrid, 13 de agosto de 1663, AGS, Contaduría Mayor de Cuentas, 3. Época, legajo 2985, exp. 13.

${ }^{20}$ Cuentas de la capilla de la embajada española en Londres, Madrid, 13 de agosto de 1663, AGS, Contaduría Mayor de Cuentas, 3. ${ }^{\text {a }}$ Época, legajo 2985, exp. 13.
} 
chando la altura de la habitación, sin perder de vista el altar mayor, se dividió el coro a la mitad mediante una celosía. Una parte se reservó para el órgano y los cantores, y la otra, para los asistentes. Sobre este se construyó un corredor grande, con el suelo entablado y cerrado por una balaustrada de madera. Su acceso se facilitó por medio de dos nuevas escaleras, una para posibilitar la entrada a los creyentes hasta el coro y la otra hasta el corredor. La primigenia quedó reservada para los capellanes. Durante estas obras también se fabricó una sacristía más grande, detrás del altar, mientras que el confesionario mudó su ubicación a la antigua dependencia ${ }^{21}$.

\section{La capilla londinense en movimiento: Esteban de Gamarra}

Poco tiempo duró la embajada del barón de Watteville en Londres. El incidente diplomático en el que se vio implicado con el representante francés, conde d'Estrades, provocó su destitución. Con ocasión de la entrada en la corte británica del embajador de Suecia conde de Wisinsborg, el 10 de octubre de 1661 había surgido un conflicto sobre la precedencia de los coches de acompañamiento que se saldó con varios heridos y algún muerto. Ante las presiones ejercidas por Luis XIV para resarcirse de la ofensa sufrida, Felipe IV condescendió en la licencia y salida de su legado en la primavera del año siguiente ${ }^{22}$.

La excepcionalidad de las circunstancias exigió una respuesta inmediata. En Madrid se ponderó cuál sería el mejor y más rápido arreglo en esas condiciones. Como sustituto del aristócrata borgoñón, y de forma interina, se nombró a Esteban de Gamarra, a la sazón embajador en La Haya desde $1654^{23}$. Por extensión, los negocios españoles, acuciantes en una coyuntura tan decisiva para sus intereses como la década de 1660, quedaron pendientes, aguardando se cubriese la plaza vacante por otro ministro permanente ${ }^{24}$. Las razones de la elección obedecieron a la autoridad y reconocida experiencia que don Esteban había adquirido ante los Estados Generales $^{25}$. Tal designación no significaba que los asuntos neerlandeses quedasen desatendidos ante el paso de su encargado de una embajada a otra. Dada la proximidad de Bruselas, oficina central para la parte del Norte, el gobernador general de los Países Bajos, marqués de Caracena, se podría encargar de su gestión junto con el secretario, Vincent Richard, que quedaría a cargo de los papeles de la embajada ${ }^{26}$. La cercanía geográfica entre ambas urbes se ha de considerar como otro de los motivos que favorecieron su nombramiento, ya que se posibilitaba la preparación del viaje con mayor presteza que si se enviara a otro ministro desde España. Del mismo modo, la multiplicidad de materias que afectaban tanto a Inglaterra como a las Provincias Unidas advierte

${ }^{21}$ Cuentas de la capilla de la embajada española en Londres, Madrid, 13 de agosto de 1663, AGS, Contaduría

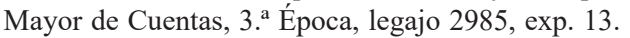

${ }^{22}$ El incidente diplomático del barón de Watteville ha sido analizado en Lemaire, 1934; Ochoa Brun, 2004: 97-159. En 1657 ya se produjo un incidente similar entre Esteban de Gamarra y el embajador francés De Thou en La Haya. Herrero, 2000: 163-164.

${ }^{23}$ Esteban de Gamarra y Contreras (1593-1671), caballero de la orden de Santiago, nació en Bruselas. Fue maestro de campo general del ejército de Flandes y castellano de Gante. Ejerció de consejero de Guerra y de Flandes, y gentilhombre de la boca del Cardenal Infante, antes de ocupar el cargo de embajador en La Haya, en sustitución de su compatriota Antoine Brun. Con anterioridad, ya había desempeñado funciones diplomáticas en el ducado de Lorena. La designación de dos borgoñones para los negociados del Norte pone de relieve el protagonismo de dichos territorios en la toma de decisiones de aquellos ámbitos.

${ }^{24}$ A comienzos de 1660, la monarquía de España seguía sin sofocar la rebelión de Portugal, pese a acabar de firmar la paz de los Pirineos con Francia. Valladares, 1998; Yetano, 2009. En relación con Inglaterra, Felipe IV había establecido un tratado de alianza con Carlos II, su pensionado mientras permanecía en el exilio. Castilla Soto, 1989: 111-124. Sin embargo, tras su restauración, el interés del Estuardo viró hacia Portugal por los beneficios que le podría reportar el matrimonio con la infanta Catarina de Bragança. Stradling, 1972: 269; Belcher, 1975: 67-88.

${ }_{25}$ Minuta de despacho de Felipe IV a Esteban de Gamarra, Madrid, 3 de noviembre de 1661, AHN, Estado, legajo 2896 , caja 1 .

${ }^{26}$ Sobre la centralidad de Bruselas en la gestión política de la monarquía de España para los asuntos del Norte, vid. Herrero Sánchez, 2011: 26. 
cómo, en gran medida, se integraban dentro de un negociado conjunto para la segunda mitad del siglo XVII.

La misión británica de Gamarra tenía carácter provisional. Estaba determinada por el tiempo que se precisase para ajustar un acuerdo proporcionado con Francia. Pese a dicha solución transitoria, el desacreditado ministro borgoñón conocería por vía indirecta de la apresurada venida de su homólogo. Asimismo, antes de recibir Watteville el despacho con la resolución de su salida, Gamarra ya había procedido a despedirse de los Estados Generales ${ }^{27}$. La llegada de esta misma noticia a la corte Estuardo también perjudicó al barón al ver desvanecida toda posibilidad de concertar una audiencia con Carlos II, que se sumaba a la orden de Felipe IV de abstenerse de cualquier conferencia con él ${ }^{28}$. Aun con tal descrédito personal, no dejó de participar de los usos acostumbrados en las despedidas diplomáticas, aceptando Watteville el encargo de instruir a su sustituto en las materias pendientes e informarle de sus confidentes y de todo cuanto fuera preciso para la dirección del servicio regio ${ }^{29}$.

Dos meses antes de abandonar la corte británica, el barón actuó como medianero de Gamarra en Londres por expresa petición suya. Así, debía ocuparse de diligenciar con el duque de Buckingham la continuación del arriendo de la York House, en los mismos términos, aunque entonces su escritura se estableció "sobre la palabra de ambos". En el transcurso del proceso negociador, y en previsión de la estacionalidad de su ida, don Esteban le preguntó acerca de si dejaría la casa amueblada o, por el contrario, se llevaría consigo todos los enseres. Precisaba de tales informaciones a fin de componerla con las tapicerías que poseía para su adorno en La Haya o, en su defecto, buscarlas según las medidas del rodeo y altura de las piezas. También le consultó el destino de algún tiro de caballos y coche con que poder moverse por las calles londinenses ${ }^{30}$.

Las conversaciones con el propietario no prosperaron ante el creciente interés mostrado hacia dicha casa por Jacobo Estuardo, hermano del monarca y duque de York. El hecho de que un miembro de la familia real quisiese tomarla para sí denota su intrínseca relevancia ${ }^{31}$. Otra de las causas fue la falta de resolución de Buckingham, quien a boca mostraba cierta disposición para continuar el alquiler, pero no respondió a la propuesta formal de Watteville en que le participaba su deseo de conservar la residencia por seis meses más para dejársela a su sustituto. De ese modo, podría "negociar más fácilmente para el demás tiempo que quisiere". Ante la indecisión del dueño, el barón emplazó a Gamarra a que efectuase las diligencias pertinentes por su parte, no sin antes advertirle que "no habiendo aquí ninguna cosa fácil, una de las más dificultosas es hallar casa" 32 .

Las pesquisas no estuvieron exentas de intentos de estafa. Con la partida del borgoñón Watteville, el que fuera su caballerizo, Cornelius van der Laan, trató de sacar provecho de la situación interina. Publicitándose como doméstico comisionado por don Esteban, acudió "a prevenir la casa, a recibir algunos criados y a hacer vestidos de librea". Sin embargo, Alonso Rancaño y Luaces, secretario de la embajada y encargado de sus papeles, descubrió tal engaño y no accedió a ninguna de sus demandas. Por ello, ofreció su ayuda a Gamarra para buscarle residencia anticipadamente, algo que este le agradecería al no conocer a tal individuo, ni haberle conferido

27 Carta del barón de Watteville a Felipe IV, Londres, 21 de diciembre de 1661, AGS, Estado, legajo 2531.

${ }_{28}$ Carta del barón de Watteville a Felipe IV, Londres, 21 de diciembre de 1661, AGS, Estado, legajo 2531.

${ }_{29}$ Minuta de despacho de Felipe IV al barón de Watteville, Madrid, 3 de noviembre de 1661, AGS, Estado, legajo 2531.

${ }^{30}$ Carta de Esteban de Gamarra al barón de Watteville, La Haya, 16 de diciembre de 1661, Archives Générales du Royaume de Belgique, Bruselas (AGRB), Ambassade d'Espagne à La Haye, 477, ff. 294rv. Sobre el estatus de las carrozas y su posición diplomática, vid. López Álvarez, 2007.

31 Carta del barón de Watteville a Esteban de Gamarra, Londres, 9 de diciembre de 1661, AGRB, Ambassade d'Espagne à La Haye, 477, f. 293r.

32 Carta del barón de Watteville a Esteban de Gamarra, Londres, 5 de enero de 1662, AGRB, Ambassade d'Espagne à La Haye, 477, f. 308v. Respecto a los alojamientos de los legados españoles en Europa, vid. Ochoa Brun, 2006: pp. 274-282. 
ningún tipo de atribución ${ }^{33}$. Sabedor de los apuros que estaba hallando el secretario del conde d'Estrades para encontrar un inmueble apropiado dentro de la ciudad para el nuevo representante francés, Rancaño quería impedir que éste "nos ganase por la mano"34. Con el conflicto de las precedencias aún latente, su propósito era posicionar a la representación española en un lugar cercano al núcleo cortesano, adaptado a las condiciones requeridas para eclipsar a su émulo galo respecto a la ubicación de la casa y la capilla. Por esta vía, la legación de Felipe IV adquiriría mayor notoriedad pública para contrarrestar las consecuencias del desafortunado incidente respecto a la preeminencia con los diplomáticos franceses ${ }^{35}$.

En esta exteriorización de la magnificencia regia, el oratorio ocupaba un lugar medular. El ostentoso aparato decorativo que Watteville había compuesto durante su breve embajada se entregó a su sucesor junto con otros elementos ordinarios, más funcionales y de exiguo valor, y "algunas curiosidades mías propias". Mientras negociaba con Buckingham el alquiler de la casa, el barón ajustó con Esteban de Gamarra la transmisión de todo lo tocante a la capilla ${ }^{36}$. Según lo convenido entre ambos, Rancaño sería el encargado de entregar al mercader Judoco Maes, residente en Londres, "las pinturas, ornamentos y otros recaudos que pertenecen a la capilla para que los guarde en su poder" hasta que llegase el nuevo embajador ${ }^{37}$. Para el efecto, y mientras se hacía efectiva la venida, el secretario alquiló un aposento donde depositar de forma segura el patrimonio material de la capilla ${ }^{38}$.

La entrega de todos estos objetos vino motivada, según el tenor de las palabras de Watteville en 1665, por varias razones. Por un lado, ante la irresolución del alquiler, parece que Gamarra mudó su opinión acerca de continuar el uso de la York House "por ser muy grande, así la casa como la iglesia". Por el otro, la suntuosidad del oratorio generaba unos elevados costes como "también los muchos alquileres y alhajas que eran menester" para el mantenimiento de la propia vivienda y la celebración del culto. Atento a lo cual, con objeto de prevenir en otro inmueble un altar decente, "necesitaba que se le diesen los ornamentos y cosas pertenecientes a este ministerio" 39 .

En mayo de 1662, y pese a seguir sin concretarse la misión diplomática de don Esteban en Londres, todos estos bienes se remitirían a La Haya, vía Ámsterdam, para terminar decorando la capilla de aquella embajada ${ }^{40}$. Los únicos recaudos que quedaron en Londres fueron un cáliz y una patena de plata, los más usados, para que Rancaño pudiera valerse de ellos y celebrase misa en su casa, con el asenso de Gamarra y el compromiso de entregárselo a Maes para que los mandase en la misma forma que el resto cuando su curador saliera de aquella corte, como aconteció apenas un mes después ${ }^{41}$.

33 Carta de Esteban de Gamarra a Alonso Rancaño, Bruselas, 28 de febrero de 1662, AGRB, Ambassade d'Espagne à La Haye, 478, ff. 23rv.

${ }^{34}$ Carta de Alonso Rancaño y Luaces a Esteban de Gamarra, Londres, 24 de febrero de 1662, AGRB, Ambassade d'Espagne à La Haye, 478, ff. 18rv.

35 Ochoa Brun, 2004: 364.

${ }^{36}$ Carta del barón de Watteville a Esteban de Gamarra, Londres, 9 de diciembre de 1661, AGRB, Ambassade d'Espagne à La Haye, 477, f. 293r.

37 Carta de Esteban de Gamarra al barón de Watteville, Gramuch, 3 de febrero de 1662, AGRB, Ambassade d'Espagne à La Haye, 477, f. 325r. Son limitadas las referencias acerca de Judoco Maes. Samuel Pepys refiere sus negocios relacionados con las plantaciones de azúcar en Brasil, concretamente, entre febrero y agosto de 1664. Pepys, 2014.

38 Carta de Alonso Rancaño a Esteban de Gamarra, Londres, 3 de febrero de 1662, AGRB, Ambassade d'Espagne à La Haye, 477, f. 3v.

39 Carta del barón de Watteville a Felipe IV, Madrid, 24 de mayo de 1665, AGS, Estado, legajo 2535.

40 Carta de Esteban de Gamarra a Alonso Rancaño, La Haya, 19 de abril de 1662, AGRB, Ambassade d'Espagne à La Hague, 477, f. 339r. El envío de los ornamentos se efectuó con un pasaporte de Carlos II, sin pagar por sus derechos. Sin embargo, no se ha localizado el expedido por los Estados Generales para el mismo fin.

${ }^{41}$ Carta de Alonso Rancaño a Esteban de Gamarra, Londres, 5 de mayo de 1662, AGRB, Ambassade d'Espagne à La Hague, 477, f. 345r; y Carta de Alonso Rancaño a Esteban de Gamarra, Londres, 11 de mayo de 1662, AGRB, Ambassade d'Espagne à La Hague, 478, f. 70r. 


\section{"Sólo los que pueden servir". El afianzamiento del patrimonio material de las capillas}

A consecuencia del incidente diplomático hispano-francés y el posterior ajuste con Luis XIV, desde Madrid se terminó por enviar a Londres un representante interino, con rango inferior al de Gamarra, mientras se apaciguaban los ánimos cortesanos. Esta decisión frustró el paso de don Esteban, a quien se encomendó reforzar la alianza con las Provincias Unidas. A la altura de 1662, la república mantenía una fuerte y creciente tensión diplomática con Inglaterra, acompañada por movimientos tendentes a negociar un tratado secreto con la Francia borbónica ${ }^{42}$. El designado para trasladarse a la corte Estuardo, en calidad de residente, fue el irlandés Patrick Moledy ${ }^{43}$. Durante los tres años que duró su estancia, profesó sus devociones en un humilde espacio de culto que en la corte española se decía "estaba en un desván sin más altar que uno con una estampa de papel" 44 .

Esta exigüidad de medios contrastó con la capilla holandesa, reforzada con parte de los trastos de Watteville. Años después, el propio barón advirtió cómo en el inventario de bienes realizado para su envío no se recogió todo lo que, en realidad, se hallaba en su altar. Durante su partida, aparte de los recaudos que tomó su secretario, los capellanes licenciados de su servicio "no hicieron escrúpulo en quedarse con algunas [cosas] con el fin de poder decir sus misas en parte secreta" 45 . Contrastando los distintos registros conservados de esta transacción, entre los bienes enviados a La Haya no figuran las pinturas de la Virgen y María Magdalena que decoraban el altar mayor, así como los cuadros del Crucificado y Nuestra Señora, colocados a ambos lados del oratorio londinense. Se desconoce el destino final de las mismas, si viajaron a España con Watteville entre la docena de "fardos grandes y pequeños de pinturas" que portaba, fueron empleadas por los capellanes en altares clandestinos o se le dio otro uso religioso o decorativo ${ }^{46}$.

La ausencia de tales obras pictóricas no desvirtuó la capilla de La Haya. Antes bien, todos aquellos objetos contribuyeron a engrandecer su esplendor ${ }^{47}$. En los primeros años de su legación, Gamarra había observado cuidadosamente sus instrucciones y también se encargó de componer un lujoso y espacioso oratorio en una casa, propiedad de un católico. Con una estructura similar a la de Londres, disponía de un cuerpo central de "cinco ventanas rasgadas", un confesionario, una pieza grande con tribuna para las "personas principales y encubiertas" y una habitación para el capellán mayor. En origen, la decoró con un retablo y una imagen de la Virgen "de bulto", entre otros ornamentos financiados por la real hacienda.

Retornando al lado inglés del Canal de la Mancha, en 1665 arribó en la corte Estuardo el conde de Molina, designado embajador ordinario en sustitución de Moledy ${ }^{48}$. Como advirtiera Watteville, encontrar residencia fue uno de los primeros inconvenientes que tuvo que

42 Herrero Sánchez, 2002: 331-376.

43 Patrick Moledy, oriundo del condado de Wexford, se exilió al continente tras la guerra civil inglesa. Durante su estancia en Bruselas, en 1650 actuó como agente de los obispos irlandeses y entabló amistad con el duque de Ormond. En esos años, también actuó como gentilhombre del archiduque Leopoldo Guillermo, quien le enviaría a Madrid para distintos asuntos. En España, sirvió como doméstico del duque de Medina de las Torres. Fue designado residente en Londres en 1662 por su dominio del inglés y la recomendación de su influyente patrón, posiblemente como medio para ampliar su radio de acción política tras el deceso del valido oculto Luis Méndez de Haro.

${ }_{44}$ Consulta del consejo de Estado, Madrid, 10 de marzo de 1669, AGS, Estado, legajo 3972. Para las capillas disimuladas en casas ordinarias durante los siglos XVII y XVIII en el contexto septentrional, vid. Kaplan, 2002: 10311064.

45 Carta del barón de Watteville a Blasco de Loyola, Madrid, 24 de mayo de 1665, AGS, Estado, legajo 2535.

${ }^{46}$ Carta de Esteban de Gamarra a los Estados Generales, La Haya, 20 de mayo de 1662. Nationaal Archief Den Haag (NADH), Staten-Generaal, Inv. 7056.

47 Sobre el oratorio diplomático de La Haya, vid. Bongaerts, 1866; Knuttel, 1894 y Alberts, 1916. La autora se encuentra realizando un estudio comparativo de las capillas de las embajadas españolas en Londres, La Haya y Copenhague-Hamburgo.

48 Antonio Mexía de Tovar y Paz (1617-1674), III conde de Molina y caballero de la orden de Santiago, descendía de una ilustre familia de origen segoviano, vinculada a la Mesta y a la gestión de las finanzas de la Real Hacienda. La 
afrontar el nuevo legado. A consecuencia del brote de peste que sacudía Londres, no pudo hallar una casa céntrica. Su primera embajada se instaló en la periférica Chelsea, en otra vivienda propiedad del duque de Buckingham ${ }^{49}$. En la ribera del Támesis, a tres millas del centro, esta distancia de prevención no disuadió a los fieles de acudir al oratorio que había compuesto, pues el altar español se había convertido en un reconocido referente para el catolicismo inglés. Pese a no disponer de ornamentos suficientes, ni tan siquiera un misal, tales ritos se oficiaban con el decoro que las circunstancias le permitían ${ }^{50}$. Esta carencia se atribuía a la entrega de la mayor parte de los objetos de la capilla que se hizo a Esteban de Gamarra tres años antes ${ }^{51}$.

Para acomodar su capilla y devolverla a su dignidad debida, sin ocasionar gastos adicionales a la real hacienda, el ministro reclamó a su homólogo en La Haya la devolución de aquellos trastos que, a todos los efectos, pertenecían al oratorio de Londres. En su petición especificó que únicamente le enviasen aquellos que, habiendo sido reconocidos por su confesor, podrían servirle, pues en algunos "costará más el porte que ellos valen" 52 . El mejor medio para su retorno era por Ostende, vía Lille y Amberes, conforme a la recomendación del conde ${ }^{53}$. Sin embargo, don Esteban no parecía dispuesto a restituir la totalidad de los bienes recibidos. Su razonamiento se reducía a los elevados gastos que generarían algunos "de mucho bulto" e importar más el transporte que su valor real, caso de un pesado sagrario de madera en desuso o algunos candelabros de cobre que "estaban dorados con oro y no con fuego, y así voló el oro" 54 . Imbuido por el pragmatismo y la precisión de ornamentos, Molina no dejó de demandar la custodia y los candelabros, aun desdorados, ya que estimaba menor gasto la reparación que la compra de otros nuevos ${ }^{55}$.

Los objetos servibles fueron enviados por medio del mercader sefardita portugués, residente en Amberes, Rodrigo Gomes Dias ${ }^{56}$. En el inventario de los cinco cajones que los portaban se incluyeron las representativas pinturas del apostolado y del Salvador. Sin embargo, conforme a la mera relación, el conde se persuadió de considerar cómo "ha de haber más para estar en la sacristía que en el altar". Pese al estado de conservación que se presumía de tales bienes, Gamarra también incluyó otros productos ajenos a la religión. Se trataba de una caja de hierbas del Paraguay y cacao de Jamaica, cuyo fuerte amargor recomendaba se contrarrestase con "paciencia y echar más azúcar" 57 . Junto a la circulación de objetos devocionales, los productos atlánticos

trayectoria diplomática de este aristócrata le llevó a fungir misiones diplomáticas en París, Venecia, Bruselas e Inglaterra al servicio de Felipe IV y Carlos II.

49 Carta de Richard Fanshaw a Carlos II, Madrid, 24 de junio de 1665, TNA: PRO, State Papers 94/49, f. 12v; y Cartas del conde de Molina a lord Arlington, Londres, 11 y 13 de julio de 1665, TNA: PRO, State Papers 94/49, ff. $27 \mathrm{r}$ y $29 \mathrm{r}$.

${ }_{50}$ Carta del conde de Molina a Felipe IV, Londres, 24 de abril de 1665, Archivo Histórico de la Nobleza, Toledo (AHNOB), Fernán Núñez, C. 970, D. 4; y Carta del conde de Molina a Felipe IV, Londres, 10 de julio de 1665, AHNOB, Fernán Núñez, C. 970, D. 4.

${ }^{51}$ Despacho de Felipe IV al conde de Molina, Madrid, 3 de junio de 1665, AHNOB, Fernán Núñez, C. 970, D. 4.

52 Carta del conde de Molina a Esteban de Gamarra, Londres, 27 de abril de 1665, AGRB, Ambassade d'Espagne à La Haye, 478, f. 93v.

${ }_{53}$ Carta del conde de Molina a Esteban de Gamarra, Londres, 8 de mayo de 1665, AGRB, Ambassade d'Espagne à La Haye, 478, f. 95r.

${ }^{54}$ Carta de Esteban de Gamarra al conde de Molina, La Haya, 22 de mayo de 1665, AGRB, Ambassade d'Espagne à La Haye, 478, f. 101r.

55 Carta del conde de Molina a Esteban de Gamarra, Londres, 8 de junio de 1665, AGRB, Ambassade d'Espagne à La Haye, 478, f. 111r.

56 Varela Flor, 2015: 366. La actividad mercantil de la comunidad sefardita en los puertos neerlandeses, así como su relación con la embajada española en La Haya se analiza en Israel, 1990: 333-448; 1992; 1997: 145-217, 375-410; y Herrero Sánchez, 2011: 39; 2016: 445-472.

57 Carta de Esteban de Gamarra al conde de Molina, La Haya, 12 de junio de 1665, AGRB, Ambassade d'Espagne à La Hague, 478, f. 113v. 
también tuvieron cabida en estos intercambios diplomáticos y ponen de manifiesto su valor simbólico y las nuevas pautas de consumo en Europa ${ }^{58}$.

Finalizada la pestilencia, y tras el devastador incendio que asoló media ciudad en 1666, la corte regresó a Londres un año después ${ }^{59}$. Siguiendo los pasos regios, el ministro español se instaló en la York House. El alquiler fue posible por un nuevo acuerdo con el duque de Buckingham, como ya hiciera en Chelsea ${ }^{60}$. En esta ocasión no halló tantos inconvenientes, a tenor del alza de los costes de las viviendas que causó el fuego. Aquel edificio que acogiera la capilla de Watteville recobró su porte y la nueva se adornó con muchos de los ornamentos devueltos por Gamarra. Por su parte, en 1671, tras la muerte de don Esteban, su sustituto, Manuel Francisco de Lira, se encontraría con el oratorio de La Haya desprovisto temporalmente de las pinturas de devoción que lo decoraban ${ }^{61}$. Esta circunstancia se debió al requerimiento de los herederos del finado embajador de todo cuanto había aportado de sus pertenencias particulares. Además de conocer cómo el lienzo central del retablo era prestado, para llenar los "blancos" que habían dejado las que se quitaron Lira hubo de encargar nuevas obras y adquirir otros adornos e instrumentos litúrgicos, generando nuevos gastos a la corona ${ }^{62}$.

Con tales premisas, en una de sus primeras cartas a Carlos II, el enviado español especificó cómo las alhajas y todo cuanto obrase en poder del capellán mayor, el jesuita Lodewijk van der Beek, componía el patrimonio material de la capilla holandesa. Esta concepción se insertaba en el proceso de institucionalización de las embajadas ${ }^{63}$. Tal fiscalización y control de los bienes no fue arbitraria, sino respondía a ciertos abusos e irregularidades que habían arraigado en su uso y privatización, tanto en La Haya como en Londres. La necesidad de inventariar cuanto definía esta habitación como espacio de culto u oratorio público se iría configurando en base a la práctica ordinaria. Con independencia de lo aportado y cedido del ajuar propio, se estableció tácitamente una transmisión formal de los "trastos" del oratorio para prevenir la dispersión y la compra de otros, salvo si fuese precisa por estar inservibles. En términos similares al mantenimiento de las casas, el ministro saliente dejaba al capellán mayor lo que hubiese heredado de su predecesor y lo que hubiera pagado "por cuenta de la real hacienda" durante su embajada. Para ello, daba relación de los objetos decorativos e instrumentales que emplearía el siguiente representante regio $^{64}$.

Al igual que sucediera en el altar holandés, cuya conexión con su homólogo londinense trascendió la circulación de objetos, la calidad y disposición de las piezas de arte y los adornos recuperados por el conde de Molina, traspasados al nuevo embajador español en Inglaterra, Marcos Alberto de Oñate, pudieron motivar la referida estimación de su capilla. Objetos y simbólicas pinturas sirvieron para visibilizar la intencionalidad confesional del monarca patrocinador o el proselitismo decorativo con que persuadir a los católicos. Todo ello contribuiría a redimensionar el valor conferido al oratorio diplomático. El recorrido y el alcance de estos elementos, contextualizados en sus respectivas realidades políticas y religiosas, y bajo la administración del embajador, posibilita la profundización en la naturaleza de estos centros de poder católicos en dos de las urbes protestantes más significativas del norte de Europa con representación española: Londres y La Haya.

58 Sobre la circulación de productos atlánticos, vid. Aram/Yun, 2014.

59 En relación al Great Fire de 1666, vid. Hanson, 2001; Tinniswood, 2003.

${ }^{60}$ Cartas del conde de Molina, Londres, 27 de diciembre de 1667, TNA: PRO, State Papers 94/53, f. 140r.

${ }^{61}$ Manuel Francisco de Lira (1631-1693) inició su carrera en el ejército de Flandes como paje del Cardenal Infante. Dentro de la esfera cortesana, desposó a Jerónima de la Torre y actuó como conductor de embajadores antes de marchar a las Provincias Unidas como enviado extraordinario. Durante su legación fue nombrado caballero de la Orden de Santiago. En 1679 regresó a Madrid donde desarrollaría una larga trayectoria en el ministerio.

${ }^{62}$ Carrió-Invernizzi, 2016: 223-230.

${ }^{63}$ Sabbatini / Volpini, 2011.

${ }^{64}$ Carta de Manuel de Lira a Carlos II, La Haya, 20 de octubre de 1671, Biblioteca Nacional de España, Madrid (BNE), Mss. 13372. 
Bibliografía

Ago, Renata (2006): Il gusto delle cose. Une storia degli oggetti nella Roma del Seicento, Roma: Donzelli Editore. Alberts, P. (1916): De Sinte Theresia-kerk op het Hooge Westeinde, La Haya, A.N. Govers.

Alzina, José Pablo (2001): Embajadores de España en Londres. Una Guía de Retratos de la Embajada de España, Madrid: Ministerio de Asuntos Exteriores, pp. 120-134.

Aram, Bethany / Yun Casalilla, Bartolomé (eds.) (2014): Global Goods and the Spanish Empire, 1492-1824. Circulation, resistance and diversity, Houndsmills: Palgrave Macmillan.

Alloza Aparicio, Ángel (2015): Diplomacia caníbal. España y Gran Bretaña en la pugna por el dominio del mundo, 1638-1660, Madrid: Biblioteca Nueva.

Barrio Moya, José Luis (1996): "El pintor José García Hidalgo, tasador de las pinturas de don Manuel Coloma, segundo marqués de Canales (1713)". En: Murgetana, 92, pp. 61-75: 70-75.

Belcher, Gerard L. (1975): "Spain and the Anglo-Portuguese Alliance of 1661: A reassessment of Charles II's foreign policy at the Restoration". En: Journal of British Studies, 15, 1, pp. 67-88.

Bongaerts, P. G. (1866): De St. Theresia-kerk weleer de koninklijke kapel van Spanje, La Haya: Ten Hagen.

Bravo Lozano, Cristina (2014): Tierras de Misión. La política confesional de la Monarquía de España en las Islas Británicas, 1660-1702. Tesis doctoral inédita. Madrid: Universidad Autónoma de Madrid.

Bravo Lozano, Cristina (2015): “¿Antemural de la fe o tierras de misión? Reflexiones en torno al Norte y la proyección confesional de la monarquía de España, 1665-1700”. En: Pedro García Martín/Roberto Quirós Rosado/Cristina Bravo Lozano (eds.), Antemurales de la fe. Conflictividad confesional en la Monarquía de los Habsburgo, 1516-1714, Madrid: Ministerio de Defensa-UAM Ediciones.

Carrió-Invernizzi, Diana (2013): "Diplomacia informal y cultura de las apariencias en la Italia española". En: Bravo Lozano, Cristina/Quirós Rosado, Roberto (eds.): En tierra de confluencias. Italia y la Monarquía de España, siglos XVI-XVIII, Valencia: Albatros Ediciones, pp. 99-109.

Carrió-Invernizzi, Diana (2016): "Manuel de Lira, Spanish Ambassador to The Hague (1671-1678). The home of the ambassador and his role as agent of artists and art collectors". En: Carrió-Invernizzi, Diana (ed.), Embajadores culturales. Transferencias y lealtades de la diplomacia española en la Edad Moderna, Madrid: UNED, pp. 205-235.

Castilla Soto, Josefina (1989): "Las relaciones entre Felipe IV y Carlos II de Inglaterra durante el protectorado de Cromwell (1656-1659)". En: Espacio, Tiempo y Forma, 2, pp. 111-124.

Colomer, José Luis (ed.) (2003): Arte y diplomacia de la Monarquía Hispánica en el siglo XVII, Madrid: Centro de Estudios Europea Hispánica.

Cunningham, Peter (1849): A Handbook for London. Past and Present, Londres: John Murray.

Hanson, Neil (2001): The Dreadful Judgment: The True Story of the Great Fire of London, Nueva York: Doubleday.

Herrero Sánchez, Manuel (2000): El acercamiento hispano-neerlandés (1648-1678), Madrid: CSIC.

Herrero Sánchez, Manuel (2011): "Republican diplomacy and the power balance in Europe". En: Alimento, Antonella (ed.), War, trade and neutrality. Europe and the Mediterranean in the Seventeenth and Eighteenth Centuries, Milán: FrancoAngeli, pp. 23-40.

Herrero Sánchez, Manuel (2016): “Conectores sefarditas en una Monarquía policéntrica. El caso Belmonte/Schonenberg en la articulación de las relaciones hispano-neerlandesas durante la segunda mitad del siglo XVII”. En: Hispania, LXXVI, 253, pp. 445-472.

Israel, Jonathan I. (1990): Empires and Entrepots: Dutch, the Spanish Monarchy and the Jews, 1585-1713, LondresRonceverte: The Hambledon Press.

Israel, Jonathan I. (1992): La judería europea en la era del mercantilismo (1550-1750), Madrid: Cátedra.

Israel, Jonathan I. (1997): Conflicts of Empires. Spain, the Low Countries and the Struggle for World supremacy, 15851713, Cambridge: Cambridge University Press.

Jacobsen, Helen (2012): Luxury and Power. The material world of the Stuart Diplomat, 1660-1714, Oxford: Oxford University Press.

Kaplan, Benjamin J. (2002), "Diplomacy and domestic devotion: embassy chapels and the toleration of religious dissent in Early Modern Europe". En: Journal of Early Modern History, 6, 4, pp. 341-361.

Kaplan, Benjamin J. (2002): "Fictions of Privacy: House Chapels and the Spatial Accommodation of Religious Dissent in Early Modern Europe". En: The American Historical Review, 107, 4, pp. 1031-1064.

Knuttel, W.P.C. (1894): "Vergaderplaatsen der katholieken te's-Gravenhage in de zeventiende eeuw". En: Archief voor Nederlandse Kerkgeschiedenis, 5, pp. 106-110.

Lemaire, L. (1934): “L'ambassade de comte d'Estrades a Londres en 1661: L'affaire 'du pas"'. En: Annuaire-Bulletin de la Société de l'histoire de France, 71, 2, pp. 181-226.

Leti, Gregorio (1685): Il ceremoniale historico e político, Amsterdam: per Giovanni \& Egidio Jansonio a Waesberge.

Loomie, Albert J. (1987): “London's Spanish Chapel before and after the Civil War”. En: Recusant History, 18, pp. 402417.

López Álvarez, Alberto (2007): Poder, lujo y conflicto en la Corte de los Austrias. Coches, carrozas y sillas de mano, 1550-1700, Madrid: Polifemo.

Ochoa Brun, Miguel Ángel (2004): "El incidente diplomático hispano-francés de 1661”. En: Boletín de la Real Academia de la Historia, 101, cuaderno 1, pp. 97-159.

Ochoa Brun, Miguel Ángel (2006): Historia de la diplomacia española, Madrid: Ministerio de Asuntos Exteriores, vol. 8. 
Pepys, Samuel (2014): Diarios, Sevilla: Renacimiento.

Sabbatini, Renzo y Volpini, Paola (eds.) (2011): "Sulla diplomazia in Età Moderna. Politica, economia, religione”. En: Annali di Storia Militare europea, 3.

Sanz Camañes, Porfirio (2015): "Las instrucciones diplomáticas de los embajadores españoles en Inglaterra durante el siglo XVII". En: Revista de Historia Moderna, 33, pp. 11-31.

Stradling, R. A. (1972): "Spanish conspiracy in England, 1661-1663”. En: The English Historical Review, 87, 343, pp. 269-286.

Storrs, Christopher (2009): "The Role of Religion in Spanish Foreign Policy in the Reign of Carlos II”. En: Onnekink, David (ed.), War and Religion after Westphalia, 1648-1713, Farnham: Ashgate, pp. 25-46.

Storrs, Christopher (2012): "La diplomacia española durante el reinado de Carlos II: una Edad de Oro o ¿quizá de Plata?”. En: Sanz Camañes, Porfirio (ed.), Tiempo de cambios. Guerra, diplomacia y política internacional de la Monarquía Hispánica, Madrid: Actas, pp. 21-53.

Tinniswood, Adrian (2003): By Permission of Heaven: The Story of the Great Fire of London, Londres: Jonathan Cape.

Trimble, William Raleigh (1946): “The Embassy Chapel Question, 1625-1660”. En: The Journal of Modern History, 18, 2, pp. 97-107.

Valladares, Rafael (1998): La rebelión de Portugal. Guerra, conflicto y poderes en la monarquía hispánica, 1640-1680, Valladolid: Junta de Castilla y León.

Varela Flor, Susana (2015): “D. Francisco de Melo Manuel da Câmara: biografia, património, estatuto social e fidelidades (1626-1678)”. En: Análise Social, 215, 2, pp. 356-381.

Watkins, John (2008): “Towards a New Diplomatic History of Medieval and Early Modern Europe". En: Journal of Medieval and Early Modern Studies, 38, 1, pp. 1-14.

Yetano, Isabel (2009): Relaciones entre España y Francia desde la paz de los Pirineos (1659) hasta la Guerra de Devolución (1667), Madrid: Fundación Universitaria Española.

Fecha de recepción: 12-VIII-2016

Fecha de aceptación: 21-XII-2016 